BOGDAN MARKOVIĆ, Ph.D. ${ }^{1}$

(Corresponding author)

E-mail: b.markovic@tehnikum.edu.rs

MILAN MARKOVIĆ, M.Sc. ${ }^{2}$

E-mail: kimi.kimi1988@gmail.com

${ }^{1}$ Academy of Applied Technical Studies Belgrade

College for Traffic, Mechanical Engineering

and Environmental Engineering

Katarine Ambrozić 3, 11000 Belgrade, Serbia

${ }^{2}$ MTT - SRB Consultancy, DOO Beograd-Stari Grad

Kralja Milana 20, 11102 Belgrade, Serbia
Transport Logistics Original Scientific Paper Submitted: 21 June 2021 Accepted: 25 Oct. 2021

\title{
DUAL APPROACH IN THE APPLICATION OF GEOMETRIC INTERPRETATION OF LINEAR PROGRAMMING ON THE ORGANISATION OF GOODS DISTRIBUTION
}

\begin{abstract}
The topic of the paper is the application of dual approach in formulation and resolution of goods distribution tasks problems. The gap in previous goods distribution research is the absence of the methodologies and goods transportation calculation methods for manufacturing companies with not too large amount of goods distribution whereby goods distribution is not the core activity. The goal of this paper is to find a solution for transportation in such companies. In such cases it is not rational to procure a specific software for the improvement of goods transportation but rather apply the calculation presented in this paper. The aim of this paper from mathematical aspect is to show the convenience of switching from the basic geometric interpretation of linear programming applied on transportation tasks to dual approach for the companies with too many costs limitations per transport task but not enough available transportation means. Recent research studies that use dual approach in linear programming are generally not applied to transportation tasks although such approach is very convenient. The goal of the paper is also to resolve transportation tasks by both primal and dual approach in order to prove the correctness of the method.
\end{abstract}

\section{KEYWORDS}

goods distribution; primal - dual approach; linear programming.

\section{INTRODUCTION}

Linear programming is widely applied and primarily conceived for goods distribution tasks and transportation problems $[1,2]$. Geometric interpreta- tion of linear programming was used from the beginning for solving the numerous tasks in logistics, but the simplex method together with a wide variety of algorithms took priority primarily due to its ability to be used in software for logistics [3]. Such software is of great interest for logistics and goods transportation companies [4]. The aim of the authors is to upgrade the bid of numerical support for goods transportation in order to fulfil the necessity for goods transportation expressed by the numerous manufacturing companies whose primary activity is goods production. A great number of such companies use their own transport means for transportation of their products. They have no logistics software nor agreements with the transport companies. By analysing numerous companies with small a series of different kinds of goods, the authors came up with the idea to fill the gap between the necessity of software usage and finding the ad hoc solutions for goods transportation which is not the core activity of such company. In particular, the following applies to such companies in terms of goods transportation:

- different kinds of goods types,

- various destinations,

- relatively small number of transportation means,

- low level of compatibility of transportation means with transport court,

- numerous limitations originated by the previously mentioned items.

According to the above, the contribution of this paper is to present the layout of the solution, an algorithm that could be used for resolving the 
transportation tasks with some limitations with respect to the realisation of transportation tasks and with a small number of various available means of transportation. In the specific case explored in the paper, the company has to comply with four limitations (constraints) with two various means of transportation (i.e., number of variables, please see chapter 4).

The basic goal of linear programming in goods distribution is to achieve the minimum value of the objective function representing the amount of transport costs, or on the other hand, to achieve the maximum of the objective function representing efficiency [4]. With that in mind, the aim of linear programming is also to respect all constraints to optimise the means and method of transport. For this purpose, the methods of linear programming that are used for the tasks to be realised are as follows: geometric interpretation of linear programming, simplex method, and matrix interpretation of simplex methods.

Otherwise, if the objective function represents amount of costs and all inequalities are greater than zero, then standard minimum problem [6] is present. But, if the signs of the inequalities are different to each other, standard mixed problem is present, $[1,7,8]$.

\section{METHODOLOGY}

Methodology presented in this paper is based on the application of geometric interpretation of linear programming in order to simplify the model for calculation by primal-dual method approach.

Finding the optimal solution using linear programming is widely used for solving the tasks in the field of heat and mass transport, especially in the field of flow analysis in fluid flow. The concept of linear programming is nearly 100 years old. Numerous methods for solving problems formulated by linear programming have been developed, which are based on using a variation approach, by minimising the functional of Euler's equation of behaviour description. Based on that, the extreme function is to be solved [9], as well as the system of algebraic equations that describe the constraints. The analysis of Leonid Kantorovich's work is given in papers $[2,10]$, while the analysis of Bergman's work is given in [11]. They gave contribution to the description of tasks using the primal, dual, and primal-dual method $[5,12]$. Based on this approach, a simplex method has been formulated in wide application methods, especially in the transport problem solutions $[13,14]$, as well as the numerical solution of numerous problems in this area.

According to the correlation between theory of flow in fluidics and the theory of flow in traffic and transport mentioned before, the authors of this paper are using the primal-dual method in tasks related to transportation of goods. The basic asset used in the paper is that the constraints formulated in the form of equations must be transformed into inequalities. This allows the formation of space or half space.

Nowadays, the simplex method [15] is increasingly used [16-18] for solving goods distribution tasks. The advantage of the simplex method is the application of computer support. In such way, a complex problem can be solved with a software specialised for transportation.

When it comes to production companies with smaller volume of production, which also includes the distribution of goods, a specific situation arises whereby a relatively small amount of goods is transported to a large number of destinations and the fleet is limited both in terms of capacity and in terms of compatibility with the type of goods being transported [19]. In this category of problems, the essence is to realise the transport concept in the shortest time without using a software to solve the problem of distribution of a large amount of goods [20]. For this purpose, the authors resorted to find a solution for optimal transport by using the primal-dual method, but for a specific example of goods distribution in a company in which production is not the main activity (Chapter 4). In that case, purchasing an expensive software or hiring a software company for transport design are not adequate solutions. Moreover, the costs of software support for designing the goods distribution in such a production company are too high and as such unprofitable for the secondary activity.

The use of the primal-dual approach in the way presented in the paper enables a quick analytical solution of these problems of secondary category when it comes to the activities of the company.

In geometric interpretations of linear programming where the constraints are given in the form of equations for ascertained conditions, there is no need to switch from the primal to dual except when the number of ascertained conditions is much greater than the number of variables. In 
the manufacturing companies, constraints are the costs per transport tasks which must be lower than imposed or set, whereby a minimum of the objective function is required. This function represents the minimum of the total costs of the entire realisation of the work. Then we are often faced with the situation that the number of constraints is not much greater than the number of variables, different types of vehicles, but we switch from standard maximum problem to standard minimum problem to simplify the way of getting a solution.

\section{THEORETICAL BACKGROUND}

Many interior-point methods for linear programming are based on the properties of the logarithmic Barrier function. These methods may be categorised as primal, dual, and primal-dual, and may be derived from the application of Newton's method to different variants of the same system of nonlinear equations. In each of the methods, convergence is demonstrated without the need for a no-degeneracy assumption or a transformation that makes the provision of a feasible region trivial. In particular, convergence is established for a primal-dual algorithm that allows a different step in the primal and dual variables and does not require primal and dual feasibility. According to [1], in constrained optimisation, a Barrier function is a continuous function whose value in a point increases to infinity as the point approaches the boundary of the feasible region of an optimisation problem. Such functions are used to replace inequality constraints by a penalising term in the objective function that is easier to handle. The decision variables, the constraints, and objective function are the three fundamental elements of linear programming $[6,21]$.

Dual approach applied to very small transportation problems is presented by Sharma [22], from the point of cost of shipping of unit goods from any plant or market. Two algorithms are considered as well as numerical examples. The approach is too complicated and not acceptable for commercial use. The approach is interesting, but not adequate for mass transportation. It is also inadequate for numerous and various transportation tasks explored herein. Schwinn and Werner [23], constructed dual solutions from primal solutions of the transportation problem applied in order to reduce transportation costs. In this paper three algorithms ware compared: UNIFORM, resolved by Sandi [24] and Schrijver [25], as well as SOLGEN, developed by Jeffrey and
James [26]. The comparison was laid out by the accuracy of results as well as by the computer spent time. The specificity of these papers is the need to use the appropriate software. This is not acceptable for most of manufacturing companies mentioned above. The reason is that all the presented accesses are based on dual approach to the transportation problem which needs to use hardware and software which is inadequate to the company activity. Classical approach to transportation problem is presented by Manisha [27]. The application of dual simplex method is presented as well as the application of the MODI method to resolve the transportation problem. The approach is quite simple but inadequate for a great number of various and specific transportation tasks. In the paper authored by Wawrzosek and Ignaciuk [28], the absence of dual model as subject of deeper studies is commented. That is partly true because there are numerous papers where dual approach is applied to a large number of problems in mass and heat transport as well as in logistics. In every case, the approach is worth considering but in the aspect of financial policy of a logistics company. Kedia [15] gave a variant of the simplex method applied to the standard maximum and standard minimum method. The method is applied to form the transportation process. The MODI method has been applied here, similarly as in paper [27]. Deficiency of the material presented in this paper is the low number of different routes, same as in [27].

With the above analysis, the authors found a gap represented by the lack of methodology that could resolve the problem of the manufacturing company that has to optimise the transportation on numerous different routes various to each other. Some methodologies presented in the papers above need a complex software to be engaged. Other methodologies presented above are either inadequate for companies whose main activity is not logistics due to insufficient capacity or they are too complicated to be used. The focus companies in this paper are furniture manufacturing companies. Dual approach in linear programming [1] and [8] is widely applied in software mainly used by these companies, but for production process only and is not applied to transportation process. Some such furniture companies are Ivanjica Furniture Company and Ginko Company, Požega, considered through numerical example in the next chapter. The Ginko Company is producing piece furniture and organises logistics using its own trucks. 


\subsection{Application of De Morgan's laws to linear programming}

The basic parameters of Boolean algebra will be considered in order to find a general way to solve a linear programming problem when the number of constraints, the imposition, is significantly greater than the number of variables. In this case, a complementary interpretation to the previous interpretation of the task is used. Namely, the switching from primal to dual is to be realised by Augustus De Morgan's (1806-1871) laws [29].

In order to illustrate the application of these laws, a table of maxterm and minterm will be created in the form of a unit for all prime numbers from the fourth to the $15^{\text {th }}$, as well as minterms, zeros, and others in binary notation, as shown in Table 1. The notation by De Morgan's expression and Boolean algebra follows in the form of primal, i.e., maxterm functions $[29,30]$ :

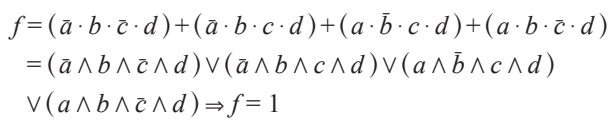

Whereas the minterm, in the form of dual, is shown as follows:

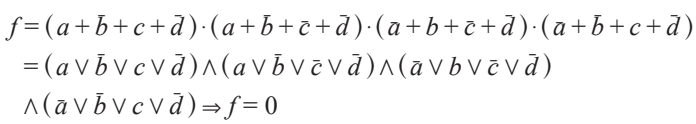

From De Morgan's expressions it is obvious that "and", represented by “"”, as well as " $\wedge$ " switches to "or", represented by "+", as well as " $\vee$ ", and v.v. At the same time, "events: $a, b c$ and $d$ " switch to their opposites: "non-events: $\bar{a}, \bar{b} \bar{c}$ and $\bar{d}$ and v.v. In Equations 1 and 2 switching from primal access to dual access is presented.

In order to prove the previously mentioned by adoption, arbitrary values for $a, b, c$ and $d$ are as follows: $1,0,0,0$.

Then, by replacement in dual (Equation 2), number 8 is obtained which corresponds to the minterm. The assumed notation is as follows: $1,0,1,0$.

Then, by replacement in Equation 2, it is to be stated that disjunction exists only with factors II, III, and IV but not with I, i.e., it is a primal number " 5 " which corresponds to the maxterm of the function but not the minterm.

By applying De Morgan's laws, e.g. by switching from the primal to dual expression referring to the minterm, the description of the state $f=0$ is transferred by the dual approach to the maxterm $f=1$ (Table 1). This approach will be used in Chapter
Table 1 -Maxterm and minterm values for numbers 1 to 15 in binary code

\begin{tabular}{||c|c|c|c|c|c||}
\hline Number & $a$ & $b$ & $c$ & $d$ & $f=\left\{\begin{array}{l}0 \\
1\end{array}\right.$ \\
\hline \hline 1 & 0 & 0 & 0 & 1 & 0 \\
\hline 2 & 0 & 0 & 1 & 0 & 0 \\
\hline 3 & 0 & 0 & 1 & 1 & 0 \\
\hline 4 & 0 & 1 & 0 & 0 & 0 \\
\hline 5 & 0 & 1 & 0 & 1 & 1 \\
\hline 6 & 0 & 1 & 1 & 0 & 0 \\
\hline 7 & 0 & 1 & 1 & 1 & 1 \\
\hline 8 & 1 & 0 & 0 & 0 & 0 \\
\hline 9 & 1 & 0 & 0 & 1 & 0 \\
\hline 10 & 1 & 0 & 1 & 0 & 0 \\
\hline 11 & 1 & 0 & 1 & 1 & 1 \\
\hline 12 & 1 & 1 & 0 & 0 & 0 \\
\hline 13 & 1 & 1 & 0 & 1 & 1 \\
\hline 14 & 1 & 1 & 1 & 0 & 0 \\
\hline 15 & 1 & 1 & 1 & 1 & 0 \\
\hline \hline
\end{tabular}

4 to describe the transfer of a transport task from minterm to maxterm. This is realised by transferring the primal to dual, or by transferring the system of constraints and objective function that refers to the minimum costs to a system of constraints expressed by inequalities of the opposite sign of inequality and objective function that will represent the maximum (maxterm) of efficiency. This is the essence of the approach to solving the transport task described in Chapter 2.

\subsection{Geometrical interpretation of linear programming}

Geometric interpretation of linear programming $[6,30]$ comes down to setting linear dependencies as constraints $g_{i}, j=1,2, \ldots, m, m$ - the total number of constraints by which domain has been formed for all variables $x_{i}$, for which the following relation must exist:

$x_{i} \geq 0, \quad i=1, \ldots, n$

where $n$ is a total number of variables.

Variables represent physical quantities, often costs in monetary units or time in seconds. In such presentation, in the coordinate system formed 
by two variables that are basic $x_{1}$ and $x_{2}$, domain takes place as inner area bounded by polygon lines representing constraints $g_{j}$. The domain [30] is to be formed by intersection of lines representing the mentioned constraints and the area of each variable being defined in 3. Each non-basic variable is expressed as a function of basic variables. Favourable states exist along the perimeter of the polygon in case when constraints are defined only by equations or by inequalities when the number of variables is equal to the number of basic variables, $b=2$. But in the case when constraints are inequalities, with the number of variables greater than the number of basic variables $b=2$, favourable states are located within the domain, i.e., the inner area of the polygon. The following constraints must be met:

$n<m+b, n \neq m, n>1$

Extreme values are in the vertices of the polygon, and after defining the intersections of the lines, they are located in one or more intersection points, which will be illustrated by an example of a task in the field of transport [30, 31].

\subsection{Dual approach}

As mentioned before, it is not rational to use the geometric interpretation of linear programming due to the lack of numerical approach and the impossibility of applying it in the case of a number of imposed states described by the system of inequalities 4. Having in mind the dual approach, expressed by the Equations 1 and 2, as well as the fact that the number of variables (2), is less than the number of constraints (4), according to 4 , it is rational to apply the dual approach. This is primarily expressed in cases of problem description when the number of inequalities is significantly greater than the number of variables. Then the geometric interpretation of linear programming is practically impossible to apply and the primal case is a system of a large number of inequalities. Therefore, it is rational to switch from the primal case to dual case. An example in the next chapter will illustrate this transition through the dual approach of transition from the standard problem of maximum to the standard problem of minimum with the transition from the primal approach to dual. Therefore, the standard minimum problem will be dual for the primal maximum problem. If they exist, the solutions must be identical and physically possible in both cases.

\subsection{Standard maximum problem}

The objective function for standard maximum problem in transport $[8,30]$ is represented by daily earnings from the exploitation of $p$ types of means of transport on $m$ transportation routes. It is expressed by the following relation:

$z_{\max }=c_{1} \cdot x_{1}+c_{2} \cdot x_{2}+\ldots+c_{p} \cdot x_{p}$

If the imposed constraints from the point of view of exploitation costs are in the following form:

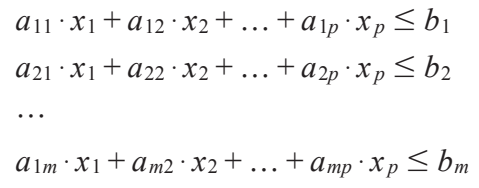

then this is equivalent to matrix notation:

$$
\begin{aligned}
& z_{\max }=\sum_{1}^{p} c_{i} x_{i}=\left[c_{1}, c_{2}, \ldots, c_{p}\right] \cdot\left[\begin{array}{llll}
x_{1} & x_{2} & \ldots & x_{p}
\end{array}\right]^{T} \\
& {\left[\begin{array}{cccc}
a_{11} & a_{12} & \ldots & a_{1 p} \\
a_{21} & a_{22} & \ldots & a_{2 p} \\
\ldots & \ldots & \ldots & \ldots \\
a_{m 1} & a_{m 2} & \ldots & a_{m p}
\end{array}\right] \cdot\left\{\begin{array}{l}
x_{1} \\
x_{2} \\
\ldots \\
x_{p}
\end{array}\right\} \leq\left\{\begin{array}{l}
b_{1} \\
b_{2} \\
\ldots \\
b_{m}
\end{array}\right\} \Leftrightarrow[A] \cdot\{x\} \leq\{b\}}
\end{aligned}
$$

In expressions 5-7, the symbols are as follows:

$c_{i}$ - daily exploitation costs per mean type $i$, $i=1,2, \ldots, p$,

$p \quad-$ total number of various types or manufacturer of transport means,

$x_{i} \quad$ - total number of means type $i$,

$a_{i j} \quad$ - daily exploitation costs of means type $i$ on route $j$,

$j=1,2, \ldots, m, m-$ total number of routes on which transport is being realised,

$b_{j} \quad-$ total daily exploitation costs caused by all transport means on route $j$,

$z_{\max }$ - total daily earnings realised by all means on all routes.

In the text that follows, authors will use an abbreviation for monetary units in the following form: "mon.units".

It is important to emphasise that physical feasibility is represented by the circumstantial of non-negativity of all variables:

$x_{i} \geq 0, \quad i=1,2, \ldots, p$

The basic problem that arises in the description of the expression 7 is that there is a system of inequalities. In order to transform system of inequalities to a system of equations, the system 7 will be extended by additional, fictitious means in order to obtain the desired form of description as follows: 


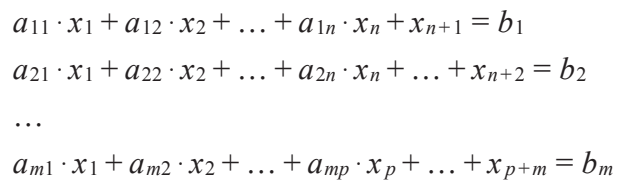

Matrix form of the objective function is as follows:

$$
\begin{aligned}
& z_{\max }=\sum_{1}^{p+m} c_{i} x_{i} \\
& =\left[c_{1}, c_{2}, \ldots, c_{p}, c_{p+1}, \ldots, c_{p+m}\right] \cdot\left[x_{1}, \ldots, x_{p}, x_{p+1}, \ldots, x_{p+m}\right]^{T}, \\
& c_{p+1}, c_{p+2}, \ldots, c_{p+m}=0 \\
& x_{i} \geq 0, i=1,2, \ldots, p, p+1, \ldots, p+m
\end{aligned}
$$

while the matrix system of constraints expressed by Equation 10 represents the following equation system:

$$
\begin{aligned}
& {\left[\begin{array}{cccccccc}
a_{11} & a_{12} & \ldots & a_{1 p} & 1 & 0 & \ldots & 0 \\
a_{21} & a_{22} & \ldots & a_{2 p} & 0 & 1 & \ldots & 0 \\
\ldots & \ldots & \ldots & \ldots & 0 & 0 & \ldots & 0 \\
a_{m 1} & a_{m 2} & \ldots & a_{m p} & 0 & 0 & \ldots & 1
\end{array}\right] \cdot\left[x_{1}, \ldots, x_{p}, x_{p+1}, \ldots, x_{p+m}\right]^{T}} \\
& =\left\{\begin{array}{l}
b_{1} \\
b_{2} \\
\ldots \\
b_{m}
\end{array}\right\} \Leftrightarrow[A] \cdot\{x\}=\{b\}
\end{aligned}
$$

\subsection{Standard minimum problem}

It is to be started from the characteristic standard minimum problem $[8,30]$. Costs of exploitation of $p$ types of means of transport on $m$ transport routes are to be established as follows:

$z_{\min }=c_{1} \cdot x_{1}+c_{2} \cdot x_{2}+\ldots+c_{p} \cdot x_{p}$

If the imposed constraints in the point of view of necessary daily capacities are as follows:

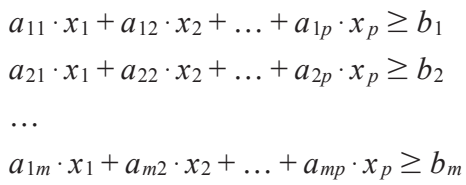

then this is equivalent to the matrix form for objective function 12 , as well as for the system of constraints 13, as follows:

$$
\begin{aligned}
& z_{\text {min }}=\sum_{1}^{p} c_{i} x_{i}=\left[c_{1}, c_{2}, \ldots, c_{p}\right] \cdot\left[x_{1}, x_{2}, \ldots, x_{p}\right]^{T}
\end{aligned}
$$

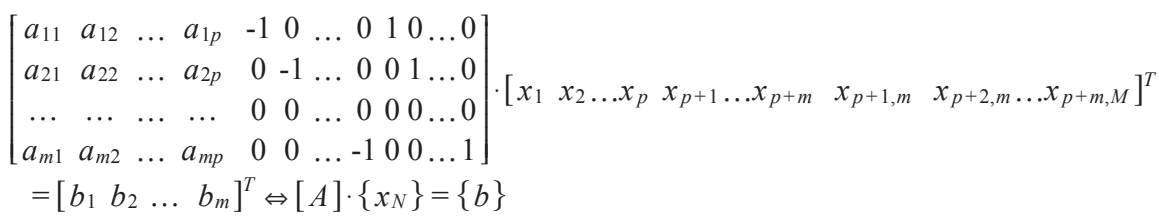$$
\left[\begin{array}{cccc}
a_{11} & a_{12} & \ldots & a_{1 p} \\
a_{21} & a_{22} & \ldots & a_{2 p} \\
\ldots & \ldots & \ldots & \ldots \\
a_{m 1} & a_{m 2} & \ldots & a_{m p}
\end{array}\right] \cdot\left\{\begin{array}{c}
x_{1} \\
x_{2} \\
\ldots \\
x_{p}
\end{array}\right\} \geq\left\{\begin{array}{c}
b_{1} \\
b_{2} \\
\ldots \\
b_{m}
\end{array}\right\} \Leftrightarrow[A] \cdot\{x\} \geq\{b\}
$$

In this relation the meaning of the symbols is as follows:

$c_{i} \quad$ - total daily exploitation costs per means type $i, i=1,2, \ldots, p$,

$p \quad-$ total number of various means types or means manufacturers,

$x_{i} \quad$ - total number of means type $i$,

$a_{i j} \quad$ - daily earnings by the exploitation of means type $i$ on the route $j$,

$m-$ total number of routes on which transport has been realised,

$b_{j} \quad-$ total earnings realised by engaging all means on the route $j$ per day, $z_{\text {min }}$ - daily earnings realised by total transport.

It is important to emphasise that physical fusibility represented by the circumstantial of non-negativity of all variables is $x_{i} \geq 0, i=1,2, \ldots, n$.

It is visible that system of inequalities 13 represents a complement form to the system 6 , i.e., dual approach. Standard minimum problem is complementary to the primal - standard maximum problem 13. As with the standard maximum problem 9, the basic problem that occurs in the description of the problem noted in 15 is that a system of inequalities exists. In order to reduce the system of inequalities to a system of equations, the system in 15 will be extended by additional variables with a negative sign, but also by the additional variables with a positive sign. Variables represent fictitious means in order to obtain the desired form of description:

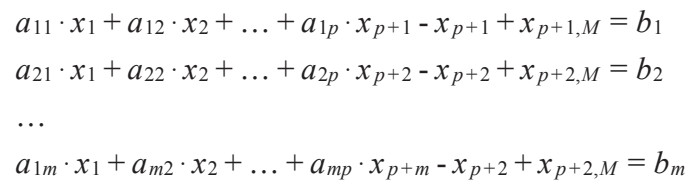

Negative sign variables are added as to allow the transformation of inequalities into equations and positive sign variables are added to prevent exiting out of the domain, i.e., the area of definition. The sum of these two variables, in each equation, represents a set of fictitious variables necessary for the 


$$
\begin{aligned}
& z_{\text {min }}=\sum_{1}^{p+2 \cdot m} c_{i} x_{i}=\left[\begin{array}{c}
c_{1}, c_{2}, \ldots, c_{p}, c_{p+1}, \ldots, c_{p+m}, c_{p+1, M}, \ldots, c_{p+m, M}
\end{array}\right] \cdot\left[\begin{array}{llll}
x_{1} & x_{2} \ldots x_{p} & x_{p+1} \ldots x_{p+m} & x_{p+1, M} x_{p+2, M} \ldots x_{p+m, M}
\end{array}\right]^{T}, \\
& c_{p+1}, c_{p+m}=0, \quad c_{p+1, M}, \ldots, c_{p+m, M}=M, \quad M \rightarrow+\infty
\end{aligned}
$$

system 16 to be equivalent to the system 13 , i.e., in matrix form 15 . Based on that, the system 16 follows in matrix form 17 .

According to 10 , the objective function $z_{\min }$ is presented in Equation 18.

By extending the constraints 8 follows: $x_{i} \geq 0$, $i=1,2, \ldots, p, p+1, M, \ldots, p+m, M$.

\section{APPLICATION OF DUAL APPROACH}

The manufacturing company considered herein produces furniture components transported by two types of transportation means owned by them. In papers [16-18], goods distribution is considered for the manufacturing and trade companies whose main activity is not transportation. Magano [17] used mixed standard maximum-minimum problem and dual approach was applied to the primal expressed by geometric interpretation of linear programming. The domain, i.e., feasible area, is formed only by two constraints, for the difference of example explored in this paper, where the number of constraints is equal to four. Having in mind that the number of constraints in paper [17] is too low, there is no need for switching to dual approach. On the other hand, dual approach is applied to the transportation problem, resolved by the Vogel and MODI method, which is more complicated. The presented methodology is useful when the number of constraints is large. In that case, the methodology which is based on geometric interpretation presented in the mentioned paper as well as in paper by Ghazali et al. [16] is convenient to be used by switching to dual. In the example that follows, four transportation tasks as constraints are to be realised by minimising costs [32] (Table 2). Methodology presented in advance is an improvement because it is not necessary to analyse the primal, presented by a geometric interpreta-

Table 2 - Description of the transportation tasks

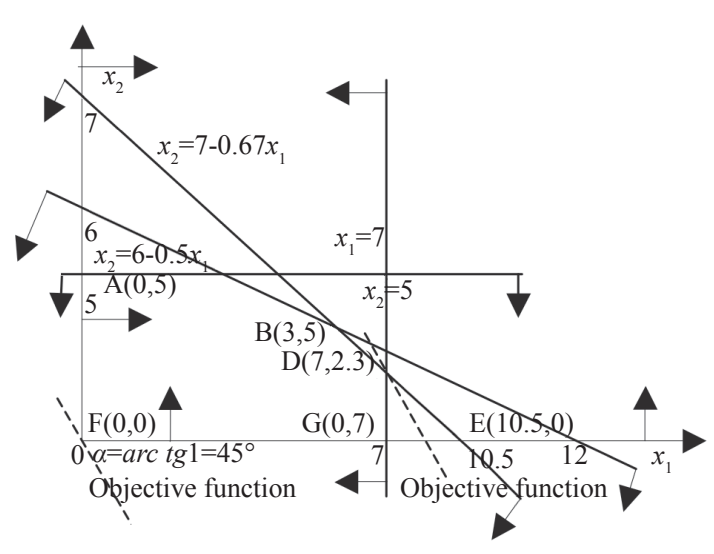

Figure 1 - Primal access resolving

tion (Figure 1) when a large number of constraints is present, but we can directly switch to dual. The example is demonstrated through dual, applied to constraints of the standard maximum problem which represents four transportation tasks realised by two different types of transportation means in order to minimise transportation costs which must not exceed the limited values and achieve maximisation of earnings. On the other hand, it is possible to find the costs per transportation task through dual approach more easily than by solving the transportation problem.

The formulation of the task is as follows:

Primal approach, with coordinates, regarding the number of engaged transportation means type $i$ :

- imposed constraints:

$2 \cdot x_{1}+3 \cdot x_{2} \leq 21,5 \cdot x_{1}+10 \cdot x_{2} \leq 60, x_{2} \leq 5, x_{1} \leq 7$

- maximum value of objective function is as follows: $z_{\max }=x_{1}+x_{2}=1 \cdot 7+1 \cdot 2.3=9.3$ monetary units, in vertex $\mathrm{D}(7,2.3)$.

Dual approach [4] with $y_{i}$ coordinates, regarding to the volume of transportation tasks, is determined by the matrix of the system which

\begin{tabular}{||c|c|c|c|c|c||}
\hline \multirow{2}{*}{$\begin{array}{c}\text { Distribution } \\
\text { task }\end{array}$} & \multicolumn{2}{|c|}{ Means of transportation, type 1 } & \multicolumn{2}{c|}{ Means of transportation, type 2 } & \multirow{2}{*}{$\begin{array}{c}\text { Max allowed costs of } \\
\text { transport per task }\end{array}$} \\
\cline { 2 - 5 } & Exploitation costs & Earnings & Exploitation costs & Earnings & 21 mon.units \\
\hline \hline 1 & 2 mon.units & 1 mon.units & 3 mon.units & 1 mon.units & 60 mon.units \\
\hline 2 & 5 mon.units & 1 mon.units & 10 mon.units & 1 mon.units & 5 mon.units \\
\hline 3 & 0 mon.units & 1 mon.units & 1 mon.units & 1 mon.units & 7 mon.units \\
\hline 4 & 1 mon.units & 1 mon.units & 0 mon.units & 1 mon.units & . \\
\hline
\end{tabular}


represents the transposed matrix of the system of the primal approach (19), so the system of inequalities was obtained as follows:

- imposed constraints:

$2 \cdot y_{1}+5 \cdot y_{2}+1 \cdot y_{4} \geq 1,3 \cdot y_{1}+10 \cdot y_{2}+1 \cdot y_{3} \geq 1$

- minimum value of objective function is as follows:

$z_{\text {min }}=21 \cdot y_{1}+60 \cdot y_{2}+5 \cdot y_{3}+5 \cdot y_{4}$

The task is to be resolved by geometric interpretation of linear programming, i.e., by forming the presentation of primal approach (Figure 1) and of dual approach (Figures 4-7). The domain relates to primal access and is bounded by vertexes. The polygonal line is merged by vertexes: $\mathrm{A}-\mathrm{B}-\mathrm{C}-\mathrm{D}$ $-\mathrm{G}-\mathrm{F}$ (Figure 1).

The value of the objective function maximum by primal access has to be, numerically, equal to the value of the objective function minimum by dual access. Maximum extreme of the objective function is represented by:

Domain has been defined by:

- inequalities 1 of system in 20, Figure 1:

$2 \cdot y_{1}+5 \cdot y_{2}+1 \cdot y_{4} \geq 1$

$2 \cdot y_{1}+5 \cdot y_{2}=u_{1} \Rightarrow y_{4} \geq 1-y_{1} \wedge y_{4} \geq 0$

- inequalities 2 of system in 20, Figure 1:

$3 \cdot y_{1}+10 \cdot y_{2}+1 \cdot y_{3} \geq 1$

$3 \cdot y_{1}+10 \cdot y_{2}=u_{2} \Rightarrow y_{3} \geq 1-u_{2} \wedge y_{3} \geq 0$

Dependence of $y_{4}$ corresponding to the dual approach of the auxiliary variable $u_{1}$ is presented in Figure 2 and dependence of $y_{3}$ corresponding to the dual approach of the auxiliary variable $u_{2}$ is given in Figure 3.

It is stated that the inequality in 22 is valid for each value for $y_{1}$ and for value $y_{2}: u_{1}, u_{2}, \in(-\infty,+\infty)$.

According to the previously mentioned and regarding to 22 , it follows: $u_{1}=2 \cdot y_{1}+5 \cdot y_{2} \geq 1$ and $u_{1}=2 \cdot y_{1}+5 \cdot y_{2}<1$, while regarding to 23 , it follows: $u_{2}=3 \cdot y_{1}+10 \cdot y_{2} \geq 1$ and $u_{2}=3 \cdot y_{1}+10 \cdot y_{2}<1$.

In order to do that, four variants of domain according to inequalities 22 and 23 , are realised:

I. $u_{1} \geq 1 \wedge u_{2} \geq 1 \Rightarrow$ intersection $3 \cdot y_{1}+10 \cdot y_{2} \geq 1 \wedge 2 \cdot y_{1}+5 \cdot y_{2} \geq 1$, follows non-empty set, solid line (Figure 4),

II. $u_{1} \geq 1 \wedge u_{2} \leq 1 \Rightarrow$ intersection $3 \cdot y_{1}+10 \cdot y_{2} \leq 1 \wedge 2 \cdot y_{1}+5 \cdot y_{2} \geq 1$, followed by empty set, dotted lines (Figure 5),

III. $u_{1} \leq 1 \wedge u_{2} \leq 1 \Rightarrow$ intersection $3 \cdot y_{1}+10 \cdot y_{2} \leq 1 \wedge 2 \cdot y_{1}+5 \cdot y_{2} \leq 1$, followed by non-empty set, solid line (Figure 6), IV. $u_{1} \leq 1 \wedge u_{2} \geq 1 \Rightarrow$ intersection $3 \cdot y_{1}+10 \cdot y_{2} \geq 1 \wedge 2 \cdot y_{1}+5 \cdot y_{2} \leq 1$, followed by non-empty set, solid line (Figure 7).

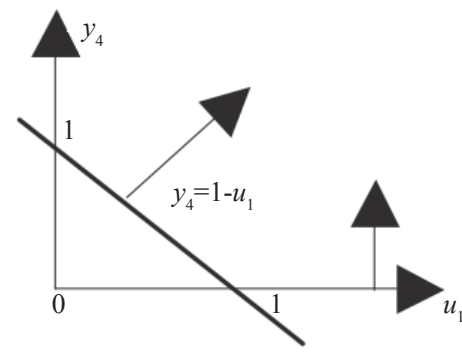

Figure 2 -Dependence of $y_{4}$ corresponding to the dual approach of the auxiliary variable $u_{1}$

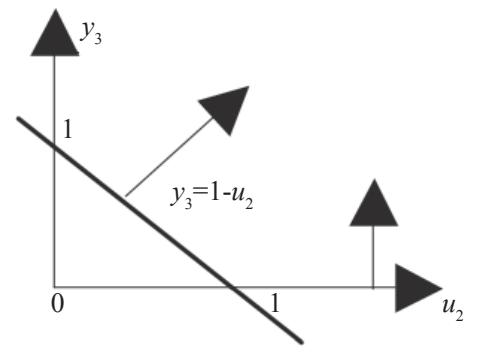

Figure 3 - Dependence of $y_{3}$ corresponding to the dual approach of the auxiliary variable $u_{2}$

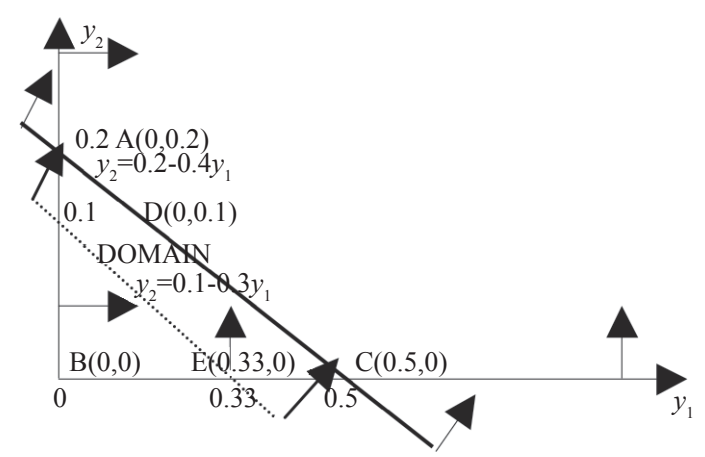

Figure 4 - Solution of dual access, variant of domain I, results in non-empty set

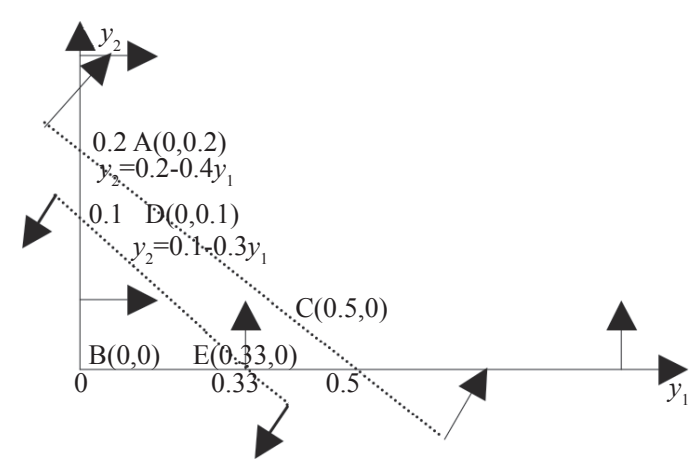

Figure 5 - Solution of dual access, variant of domain II, results in empty set

It is clear that there are three variants that result in non-empty set. It is to be stated that the condition for the solutions for $y_{3}$ (Figure 3) and $y_{4}$ (Figure 4) 


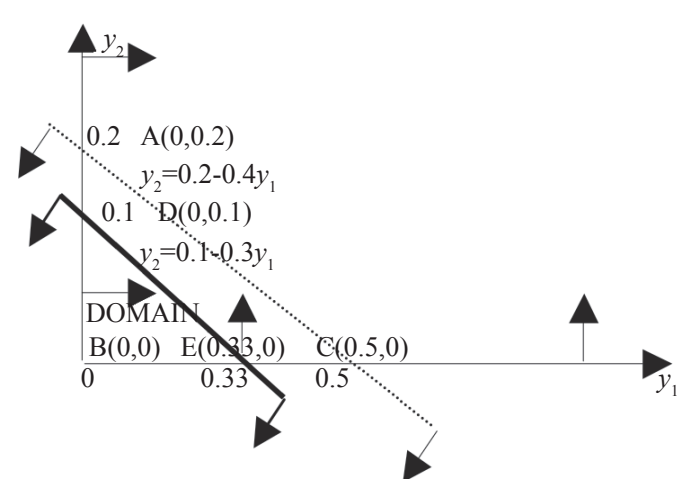

Figure 6-Solution of dual access, variant of domain III, results in non-empty set

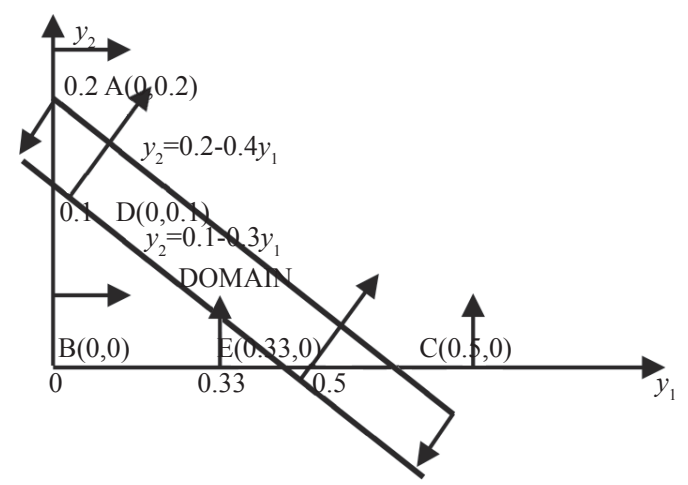

Figure 7 - Solution of dual access, variant of domain IV, results in non-empty set

exists and is as follows:

$y_{3} \geq 0 \forall u_{2} \leq 0, \quad y_{4} \geq 0 \forall u_{1} \leq 0$

These constraints are to be added to intersections from constraints: I, III, and IV. According to that, intersection $u_{1} \leq 0$ and $u_{2} \leq 0,(24)$, together with the variants of forming the area defined by inequalities, results in intersections as follows:

I. $u_{1} \geq 1 \cap u_{1} \leq 1 \Rightarrow u_{1}=1 \Rightarrow y_{4}=0$, Figure 2 and

$u_{2} \geq 1 \cap u_{2} \leq 1 \Rightarrow u_{2}=1 \Rightarrow y_{3}=0$, Figure 3,

III. $u_{1} \leq 1 \cap u_{1} \leq 1 \Rightarrow u_{1} \leq 1 \Rightarrow y_{4} \geq 0$, Figure 2 and

$u_{2} \leq 1 \cap u_{2} \leq 1 \Rightarrow u_{1} \geq 1 \Rightarrow y_{3} \geq 0$, Figure 3,

IV. $u_{1} \leq 1 \cap u_{1} \leq 1 \Rightarrow u_{1} \leq 1 \Rightarrow y_{4} \geq 0$, Figure 2 and

$u_{2} \geq 1 \cap u_{2} \leq 1 \Rightarrow u_{2}=1 \Rightarrow y_{3}=0$, Figure 3 .

It is obvious that the minimum value of the objective function could be found in the case of the variant concerning the area defined by intersections in cases I, III, and IV:

$3 \cdot y_{1}+10 \cdot y_{2}>1 \wedge 2 \cdot y_{1}+5 \cdot y_{2}>1$, domain $\infty-\mathrm{A}-\mathrm{C}-\infty$, case I, Figure 4,

$3 \cdot y_{1}+10 \cdot y_{2}<1 \wedge 2 \cdot y_{1}+5 \cdot y_{2}<1$, domain $\mathrm{D}-\mathrm{E}-\mathrm{B}$, case III, Figure 6, and

$3 \cdot y_{1}+10 \cdot y_{2} \geq 1 \wedge 2 \cdot y_{1}+5 \cdot y_{2}<1$, domain $\mathrm{A}-\mathrm{C}-\mathrm{E}-\mathrm{D}$, case IV, Figure 7.
In order to establish the domain for this problem, the task with two inequalities and four variables has to look for the values of all four variables in all vertexes of the polygonal line for these three domains. On the basis of that, the coordinates of the point in which the objective function $z_{1}(21)$ has its minimum will be determined:

- $\mathrm{D}(0,0.1,0,0.5)$

Variable $y_{4}$ becomes equal to 0.5 according to the fact that by replacing $y_{1}=0$ and $y_{2}=0.1 \quad$ in $22, \quad$ it follows: $y_{4} \geq 1-2 \cdot y_{1}-5 \cdot y_{2}$, $2 \cdot 0+5 \cdot 0.1+1 \cdot y_{4} \geq 1 \Rightarrow y_{4} \geq 0.5$.

Variable $y_{3}$ becomes equal to zero according to the fact that by replacing $y_{1}=0$ and $y_{2}=0.2$ in 23 , it follows: $y_{3} \geq 1-3 \cdot y_{1}-10 \cdot y_{2} \Rightarrow 3 \cdot 0+10 \cdot 0.1+1 \cdot y_{3} \geq 1$, $y_{3} \geq 1 \wedge y_{3} \geq 0 \Rightarrow y_{3} \geq 0$.

It follows that the objective function will have its minimum for value $y_{3}$ and $y_{4}$ as the lowest possible, which is in this case equal to $y_{3}=0$, $y_{4}=0.5$. According to that, the value for the objective function is $z_{1}=21 \cdot y_{1}+60 \cdot y_{2}+5 \cdot y_{3}+7 \cdot y_{4}=$ $21 \cdot 0+60 \cdot 0.1+5 \cdot 0+7 \cdot 0.5=9.5$ mon.units.

- E $(0.33,0,0,0.33)$

Variable $y_{4}$ becomes equal to zero, according to the fact that by replacing $y_{1}=0.5$ and $y_{2}=0$ in 22 , it follows: $2 \cdot 0.33+5 \cdot 0+1 \cdot y_{4} \geq 1 \Rightarrow y_{4}=0.33$.

Variable $y_{3}$ becomes equal to 0 according to the fact that by replacing $y_{1}=0.33$ and $y_{2}=0$ in 22 , it follows: $3 \cdot 0.33+10 \cdot 0+1 \cdot y_{3} \geq 1 \Rightarrow y_{3} \geq 0$.

It follows that the objective function will have its lowest possible minimum for value $y_{3}$ which is in this case equal to zero, too. According to that, the value for objective function is as follows: $z_{1}=21 \cdot 0.33+60 \cdot 0+5 \cdot 0+70.33=9.3$ mon.units.

- $\mathrm{C}(0.5,0,0,0)$

Variable $y_{4}$ becomes equal to zero, according to the fact that by replacing $y_{1}=0.5$ and $y_{2}=0$ in 22 , it follows, $2 \cdot 0.5+5 \cdot 0+1 \cdot y_{4} \geq 1 \Rightarrow y_{4}=0$.

Variable $y_{3}$ becomes equal to zero, according to the fact that by replacing $y_{1}=0.5$ and $y_{2}=0$ in 23 , it follows: $y_{1}=0.5$ and $y_{2}=0 \Rightarrow 3 \cdot 0.5+10 \cdot 0+1 \cdot y_{3} \geq 1 \Rightarrow$ $y_{3} \geq 0$.

It follows that the objective function will have its lowest possible minimum for value $y_{3}$ which is in this case equal to zero, too. According to that, value for the objective function is as follows: $z_{1}=2 \cdot 10.5+60 \cdot 0+5 \cdot 0+7 \cdot 0=10.5$ mon.units.

- $\mathrm{A}(0,0.2,0,0)$

Variable $y_{4}$ becomes equal to zero, according to the fact that by replacing $y_{1}=0.5$ and $y_{2}=0$ in 22 , it follows: $2 \cdot 0+5 \cdot 0.2+1 \cdot y_{4} \geq 1 \Rightarrow y_{4}=0$. 
Variable $y_{3}$ becomes equal to zero, according to the fact that by replacing $y_{1}=0$ and $y_{2}=0.2$ in 23 , it follows: $y_{1}=0$ and $y_{2}=0.2 \Rightarrow 3 \cdot 0+10 \cdot 0.2+1 \cdot y_{3} \geq 1$, $y_{3} \geq 0$.

It follows that the objective function will have its lowest possible minimum for value $y_{3}$ which is in this case equal to zero, too. According to that, value for the objective function is as follows: $z_{1}=2 \cdot 10+60 \cdot 0.2+5 \cdot 0+7 \cdot 0=12$ mon.units.

- B $(0,0,1,1)$

Variable $y_{4}$ becomes equal to zero, according to the fact that by replacing $y_{1}=0.5$ and $y_{2}=0$ in 22 , it follows: $2 \cdot 0.0+5 \cdot 0+1 \cdot y_{4} \geq 1 \Rightarrow y_{4} \geq 1$.

Variable $y_{3}$ becomes equal to 1 , according to the fact that by replacing $y_{1}=0$ and $y_{2}=0$ in 23, it follows: $y_{1}=0$ and $y_{2}=0 \Rightarrow 3 \cdot 0+10 \cdot 0+1 \cdot y_{3} \geq 1 \Rightarrow y_{3} \geq 1$.

The objective function of dual access will have its minimum in vertex $\mathrm{E}$ with coordinates: $y_{1}=0.33$ monetary units, $y_{2}=0, y_{3}=0, y_{4}=0.33$ monetary units.

The objective function for dual approach is equal to $z_{\text {min }}=21 \cdot 0.33+60 \cdot 0+5 \cdot 0+7 \cdot 0.33=9.3$ monetary units.

This corresponds to the result obtained by primal access and represents the maximum earnings by transportation process in vertex $\mathrm{D}$ with coordinates $x_{1}=7$ (average number of engaged means type 1) and $x_{2}=2.3$ (average number of engaged means type 2), as shown in 19 and Figure 1.

\section{DISCUSSION}

The methodology presented in the paper provides an answer for the request for optimisation of transport in manufacturing companies with goods distribution as non-core activity and that is the main benefit of the paper. Large number of companies have their own means of transportation and no interest to obtain a software in order to optimise the transportation method of the goods produced by them in any way. The need to improve the transportation method in order to minimise the transportation costs was the motive behind developing the presented methodology. Thus, the authors made the effort to eliminate the gap between using a specialised software for resolving goods distribution tasks in companies where logistics is the core activity and individual finding the solutions in numerous manufacture companies. Nowadays, linear programming and large variety of algorithms are applied in many types of software. However, such approach is present in most cases in the logistics companies but not in the companies that were subjects of this research.
The approach presented in this paper is the solution that needs to be applied on a great variety of goods distribution in the companies described above and could easily be realised.

Common to all of them is the presence of too many limitations for distribution tasks; low number of various types of means of transportation as well as finding the minimum of the objective function representing the cost level.

Through the presented task in the field of logistics, the paper presents the stated simplification by applying the transition from the primal access, described by the geometric presentation of linear programming, to dual approach. It is stated that the minimum of the dual objective function is equivalent to the magnitude of the maximum of the receiving objective function.

In this paper, the maximum of the objective function for primal access is in vertex D, Figure 1 and the coordinates of that point define the participation of type 1 and 2 vehicles in transport. The sum of the maximum value of the objective function is 9.3 monetary units. The same size is obtained by solving the dual task in the vertex E, where the objective function has the same minimum, i.e., 9.3 monetary units, with 10 vehicles of the first type and 10 vehicles of type 4 engaged. This also proves the correctness of the procedure applied in this paper.

\section{CONCLUSION}

The aim of the paper is to create a methodology adequate for realising an optimal transportation process in manufacturing companies in which transport is not a core activity. A lot of such companies do not have appropriate software as to resolve optimal transport. In order to that, some of them applied a dual approach to primal, mainly considered as a geometric interpretation of linear programming [16-18]. The authors took notice of this approach presented in these papers and aimed to improve it. In these papers, the primal is considered for a low number of constraints which is not common in practice. At the same time, it is not necessary to approach the dual because it is easy to resolve problem directly from the primal. On the other hand, when the number of constraints is large, it is better and easier to apply the dual approach using the minterm-maxterm method [22], in the way presented above as well as through example. The methodology presented above is novelty and fills the gap made due to the absence of a simple approach for 
numerically resolving transportation of various products to numerous destinations. The presented methodology is simple to use and adequate for solving real tasks from practice. The novelty in this paper is the notion that it is not necessary for the companies to use software support at all costs, by the reason that volume of goods to be distributed is relatively low. The benefit of this paper and the advantage of applying this methodology is primarily aimed at companies who produce and distribute goods by using their own transport means. These companies are especially characteristic for countries in transition, where mass production is not present and where production process is specific from the aspect of products getting finalised. Those include small production series and production of unique goods.

Dr BOGDAN MARKOVIĆ, dipl. maš. inž. ${ }^{1}$

E-mail: b.markovic@tehnikum.edu.rs

MILAN MARKOVIĆ, akademski master mašinstva ${ }^{2}$

E-mail: kimi.kimi1988@gmail.com

${ }^{1}$ Akademija tehničkih strukovnih studija Beograd,

Odsek za saobraćaj, mašinstvo i inženjerstvo zaštite

Katarine Ambrozić 3, 11000 Beograd, Srbija

${ }^{2}$ MTT - SRB Consultancy, DOO Belgrade - Stari Grad

Kralja Milana 20, 11102 Beograd, Srbija

\section{DUALNI PRISTUP KOD PRIMENE GEOMETRIJSKE INTERPRETACIJE LINEARNOG PROGRAMIRANJA NA ORGANIZACIJU TRANSPORTA ROBE}

\section{ABSTRAKT}

Tema rada je primena dualnog pristupa na rešavanje zadataka transporta robe. Kod dosadašnjih istraživanja na polju unapređenja distribucije robe prisutno je nepostojanje adekvatnih metodologija i matematičkih modela za proračun i optimiranje transporta kod firmi koje se bave materijalnom proizvodnjom i kod kojih organizacija transporta nije osnovna delatnost. Rešavanje problema transporta robe i unapređenje transportnog procesa kod ovakvih firmi je osnovni smisao izučavanja u ovom radu. Za navedene kompanije, koje se bave proizvodnom delatnošću i kod kojih se ne realizuje transport veće količine robe, nije racionalno nabavljanje softvera za rešavanje transportnih zadataka i unapređenje istih. $U$ skladu sa tim, Radom se daje metodološki pristup i proračun za rešavanje transportnih zadataka upravo za takve firme. Cilj rada, sa matematičkog aspekta, je prikaz pogodnosti prelaska sa osnovne, geometrijske interpretacije linearnog programiranja, na dualni pristup umesto na formiranje pa, potom, rešavanje transportnog problema. Metodologija i proračun prezenovani Radom ilustrovani su primerom reprezentativnim za kompanije kod kojih se pri definisanju transportnih zadataka javlja veći broj finansijskih ograničenja dok je, sa druge strane, broj različitih tipova transportnih sredstava prilično skroman. Postojeća istraživanja na polju primene dualnog pristupa kod linearnog programiranja nisu u velikoj meri zastupljena pri rešavanju transportnih zadataka iako je to prilična pogodnost. Motiv u radu je, rešavanje transportnog zadatka putem oba, primalnog $i$ dualnog pristupa nakon čega se iznalazi optimalni tip i broj jedinica transportnog sredstva kao i funkcija cilja za slučaj primala i duala. Upoređivanjem $i$ konstatovanjem poklapanja rezultata dokazuje se ispravnost metode.

\section{KLJUČNE REČI}

transport robe; primal - dual pristup; linearno programiranje.

\section{REFERENCES}

[1] Gill P, et al. Primal - dual methods for linear programming. Mathematical Programming. 1995;70(1): 251277. DOI: $10.1007 / \mathrm{BF} 01585940$

[2] Kutateladze S. Linear programming and Kantorovich spaces. Journal of Applied and Industrial Mathematics. 2007;1: 137-41. DOI: 10.1134/S1990478907020019

[3] Stojanović V, Spalević LJ, Bozinović M. Software application for solving the transportation problem. International Conference ERK, Portoroz, Slovenia; 2014. p. 23-26.

[4] Soonhong M, Zacharia ZG, Smith CD. Defining supply chain management: In the past, present, and future. Journal of Business Logistics. 2019;40(2): 44-55. DOI: 10.1111/jbl.12201

[5] Philip E, et al. Primal - Dual Methods for Linear Programming. University of California, San Diego, USA. Report number: SOL 91-3, 1994.

[6] Hillier S, Lieberman J. Introduction to Operations Research. New York: Mc Grow Hill Education; 2015.

[7] Mehrotra S. On the implementation of a primal - dual interior point method. SIAM Journal on Optimization. 1993;2(4): 575-601. DOI: 10.1137/0802028

[8] Tošić D. Course of Mathematics III. Belgrade: Naučna knjiga; 1993.

[9] Mc Shane KA, Monma CL, Shanno DF. An implementation of a primal - dual interior point method for linear programming. ORSA Journal on Computing. 1989;1: 7083. DOI: $10.1287 /$ ijoc.1.2.70

[10] Pratelli A. On the Equality between Monge's infinum and Kantorovich's minimum in optimal mass transportation. Annals de L'Institut Henri Poincare (B) Probability and Statistics. 2007;43(1): 1-13. DOI: 10.1016/ j.anihpb.2005.12.001

[11] Benamou J-D, et al. Iterative Bergman projections for regularized transportation problems. Society for Industrial and Applied Mathematics, Methods and Algorithms for Scientific Computing. 2015;37(2): A1111-A1138. DOI: $10.1137 / 141000439$

[12] Monteiro RDC, Adler I. Interior path following primal - dual algorithms. Linear Programming. Mathematical 
Marković B, Marković M. Dual Approach in the Application of Geometric Interpretation of Linear Programming on the...

Programming, Part I. 1989;44(1): 27-44. DOI: 10.1007/ BF02191759

[13] Vukadinović S. Transportation problem in Linear Programming. Belgrade: Naučna knjiga; 1988.

[14] Filić M. [Distribution method in linear programming]. In: Kučinić, et al. Iz matematičkog mozaika. Zagreb, Croatia: Školska knjiga; 1975. Croatian.

[15] Kedia RG. A new variant of simplex method. International Journal of Engineering and Management Research. 2013;3(6): 73-75. Available from: http://www. ijemr.net [Accessed Dec. 2013].

[16] Ghazali Z, et al. Optimal solution of transportation problem using linear programming: A case of a Malaysian Trading Company. Journal of Applied Sciences. 2012;12(23): 2430-20435. DOI: 10.3923/jas

[17] Magano M. A linear programming model for integrated baked production and distribution planning with raw material and routing consideration. Proceedings of the International Conference on Industrial Engineering and Operations Management, 2017, Bogota, Colombia; 2017. ID 261A.

[18] Aydinel M, et al. Optimization of production allocation and transportation of customer orders for a leading forest products company. Mathematical and Computer Modeling. 2008;48(7-8): 1158-1169. DOI: 10.1016/ j.mcm.2007.12.025

[19] Rushton A, Croucher P, Baker P. The Handbook of Logistics \& Distribution Management. London, U.K: The Chartered Institute of Logistics and Transport; 2010.

[20] Krynke M. Application of linear programming in supply chain management in the foundry. Proceedings $29^{\text {th }}$ International Conference on Metallurgy and Materials. 20-22 May 2020, Brno, Czech Republic; 2020. p. 12801286. DOI: $10.37904 /$ metal.2020.3648

[21] Bazaraa MS, Jarvis JJ. Linear Programming and Network Flows. Hoboken, New Jersey: John Wiley \& Sons, Inc; 2010.

[22] Sharma K. New dual based procedure for the transportation problem. European Journal of Operational Research. 2000;122(3): 611-624. DOI: 10.1016/S03772217(99)00081-8
[23] Schwinn J, Werner R. On the effectiveness of primal and dual heuristics for the transportation problem. Journal of Management Mathematics. 2019;30(3): 281-303. DOI: 10.1093/imaman/dpy011

[24] Sandi C. On a Nonbasic Dual Method for the Transportation Problem. Berlin Heidelberg: Springer Verlag; 1986. p. 65-82.

[25] Schrijver A. On the history of the transportation and maximum flow problems. Mathematical Programming. 2002;91(2002): 437-445. DOI: 101007/s101070100259

[26] Jeffrey A, James J. An algorithm for generating minimum cost network flow problems with specific structure and known optimal solutions. Networks. 1994;24(8): 445-454. DOI: $10.1002 /$ net.3230240805

[27] Manisha V. Application of a dual simplex method to transportation problem to minimize the cost. International Journal of Innovations in Engineering and Science. 2017;2(7). Available from: htpp://w.w.w.ijijes.net [Accessed July 2017].

[28] Wawrzonek J, Ignaciuk S. Dual model for classic transportation problem as a tool for dynamyzing management in a logistics company. An International Quarterly Journal on Economics of Technology and Modeling Processes. 2016;5(3): 95-100. Available from: http://yadda. icm.edu.pl/yadaa/element.baztech-2100f2fe-c687-4756b5e0-c49822c707e9/c/Wawrzosek.pdf [Accessed Mar. 2016].

[29] Kusraev G, Kutateladze S. Boolean Valued Analysis. Dordrecht, Netherlands: Kluwer Academic Publishers; 1999. DOI: 10.1007/978-94-011-4443-8

[30] Marković B. Optimisation Methods in Transport Organization and Material Handling. Belgrade, Serbia: Tehnikum Taurunum, VIŠSS, Beograd - Zemun; 2019.

[31] Ping J, Chu F. A dual-matrix approach to the transportation problem. Asia - Pacific Journal of Operational Research. 2002;19(1): 35-45.

[32] Sarode M. Application of a dual simplex method to transportation problem to minimize the cost. International Journal of Innovations in Engineering and Science. 2017;2(7); Available from: http://w.w.w.ijies.net [Accessed July 2017]. 